\title{
Solution concepts in multicriteria cooperative games without side payments
}

\author{
Lech Kruś, Piotr Bronisz \\ Systems Research Institute, Polish Academy of Sciences \\ Newelska 6, 01-447 Warszawa, Poland. \\ e-mail: krus@ibspan.waw.pl, bronisz@ibspan.waw.p1
}

\begin{abstract}
The paper presents a study of $n$-person cooperative games without side payments in the case of vector payoffs of players. Recently, much attention has focused on problems with vector payoffs in the field of game theory, since multicriteria models can better apply to real-world situations. In the paper, solution concepts are formulated and analysed. A nucleolus concept is proposed which is invariant on affine transformation of criteria and coincides with the Schmeidler nucleolus in case of unicriteria games with payments and with Raiffa-Kalai-Smorodinsky solution in case of unicriteria bargaining problem.
\end{abstract}

\section{Keywords}

multicriteria decision making, theory of cooperative games, multicriteria optimization methods, decision support systems.

\section{INTRODUCTION}

The theory of cooperative games has been intensively investigated, especially in the case of games with side payments. The most interesting results can be found in the papers by Shapley, Schmeidler, Aumann, Maschler, to mention only some leading researchers. The theory of the games without side payments has not been so developed, however some important results have been obtained, among others, by Aumann (1961), Peleg (1963), Stearns (1964), Kalai (1975). The theory of cooperative games has been developed under a general assumption that the players outcomes are measured by explicitly given utility function satisfying some assumptions. In practical problems the outcomes are usually measured by some number of criteria, and the utility function are not explicitly given. Papers dealing with cooperative games with multicriteria outcomes of players are relatively rare. We would like to mention the paper by Bergstressen, Yu (1977), where Yu' domination structures were utilized to define and analyse the cooperative games with side payments. Some number of questions to be solved were formulated. However, we have not found in the literature any paper on multicriteria games without side payments. 
In this paper we make an attempt to develop the theory of cooperative games without side payments in the case of multicriteria payoffs of the players. We do not assume any a priory given utility function of a player. However it is assumed that every player has his in mind preferences among the criteria. The preferences can be in general context dependent. Similarly as in aspiration function approach Wierzbicki $(1982,1986)$, we assume the reference points in the spaces of objectives of the players. The points define direction improving the criteria, which are used in an analogous way as in the goal attainment method Gembicki, Haimes (1975) to the sets describing payoffs of coalitions.

The study presented in the paper continues previous research of the authors on the multicriteria bargaining problem and decision support Kruś, Bronisz, Lopuch (1990), Kruś, Bronisz (1993) and on multicriteria noncooperative games Kruś, Bronisz (1994).

\section{PROBLEM FORMULATION}

Let $N=\{1,2, \ldots, n\}$ be the finite set of the players, and let $\mathcal{N}$ be the set of all nonempty subsets of $N$. For any coalition $S \in \mathcal{N}$ :

$E^{S}=\times_{i \in S} E_{i}$ be a decision space of players in $S$, where $E_{i}$ is a decision space of the $i$-th player $i \in N$.

$G^{S}=\times_{i \in S} G_{i}$ be an objective space of players in $S$, where $G_{i}$ is a $k_{i}$ dimensional Euclidean space of outcomes of the $i$-th player $i \in N$,

$Q^{S}: E^{S} \rightarrow G^{S}$ be a vector valued function defining multicriteria payoffs of players in $S$, where $Q_{i}: E_{i} \rightarrow G_{i}$ is a vector valued function of the $i$-th player payoffs.

For simplicity of notation, we assume that each player tries to maximize all his criteria. For any $x=\left(x_{i}\right)_{i \in N} \in G^{N}$ let $x^{S}=\left(x_{i}\right)_{i \in S}$ denote payoffs of the players in $\mathrm{S}$, where $x_{i}=\left(x_{i 1}, x_{i 2}, \ldots, x_{i k}\right) \in G_{i}=R^{k_{i}}$.

Let $E_{0}^{S} \subset E^{S}$ be a set of admissible decisions of the players in $S$. A cooperation of players can be defined by a collection $\left\{V^{S}\right\}_{S \in \mathcal{N}}$ of sets $V^{S}, V^{S} \subset G^{S}$, where $V^{S}=Q^{S}\left(E_{0}^{S}\right)$ denotes the set of attainable multicriteria payoffs of the players in $S$.

We employ a convention that for $x, y \in R^{m}$, and for any $m$ :

$x \geq y$ implies $x_{i} \geq y_{i}$ for all $i=1,2, \ldots, m$,

$x>y$ implies $x_{i} \geq y_{i}, x \neq y$ for all $i=1,2, \ldots, m$,

$x>>y$ implies $x_{i}>y_{i}$ for all $i=1,2, \ldots, m$

\section{Definition 1}

A multicriteria $n$-person cooperative game without side payments (n-person $\mathbf{M C C}$ game) is described by a collection $V=\left\{V^{S}\right\}_{S \in \mathcal{N}}$ of sets $V^{S}$ satisfying the following conditions:

1. $V^{S}$ is closed and nonempty subset of $G^{S}$,

2. $V^{S}$ is upper bounded, i.e. there exists $x^{S} \in G^{S}$ such that $V^{S} \subset\left\{y^{S} \in G^{S}: y^{S} \leq x^{S}\right\}$,

3. for any $x^{S} \in G^{S}, y^{S} \in V^{S}$, if there is $y^{S}<x^{S}$, then $y^{S} \in \operatorname{int}\left(V^{S}\right)$,

4. for each two coalitions $S, T \in \mathcal{N}$, such that $S \cap T=\emptyset, V^{S} \times V^{T} \subset V^{S u T}$.

The formulation of MCC game is closely related to the formulation of cooperative game without side payments given by Aumann (1967). 


\section{GENERAL MULTICRITERIA SOLUTION CONCEPTS}

We denote by $\Omega$ a class of all $n$-person MCC games. A solution concept is a function $F: \Omega \rightarrow G^{N}$, which associates to each game $V \in \Omega$ a set of payoffs $F(V) \subset V^{N}$.

\section{Definition 2}

A core of the game $V$ is the set core $(V)=\left\{x \in V^{N}\right.$ : for every coalition $S$ there is no $y^{S} \in V^{S}$, such that $y_{i}>x_{i}$ for every $\left.i \in S\right\}$.

A payoff belongs to a core if for every coalition, there is no payoff improving at least one criterion of each member.

\section{Definition 3}

A function $l_{S}: G^{N} \times \Omega \rightarrow R$ will be called an excess function for the coalition $\mathrm{S}$ if it satisfies the following conditions:

1. If $x, y \in G^{N}$ are such that $x_{i}=y_{i}$ for every $i \in S$, then for every game $V$,

$$
l_{S}(x, V)=l_{S}(y, V)
$$

2. If $x, y \in G^{N}$ such, that $x_{i}>y_{i}$ for every $i \in S$, then for every game $V$,

$$
l_{S}(x, V)<l_{S}(y, V)
$$

3. For any game $V$, if $x^{S} \in \operatorname{boundary}\left(V^{S}\right)$ then $l_{S}(x, V)=0$.

4. $l_{S}(x, V)$ is continuous jointly with respect to $x$ and $V$.

The excess function $l_{S}(x, V)$ reflects the "attitude" of coalition $S$ to the payoff $x$. The condition 1 means that the excess function does not depend on the remaining players in $N$. The condition 2 assures that if at least one criterion of some players in payoff increase, then an excess function of the coalition created by them decreases. Condition 3 divide payoffs onto 2 categories: attainable for any coalition $S$ - when $l_{S}(x, V) \geq 0$ and such that coalition can not assure - when $l_{S}(x, V)<0$. From the conditions 2 and 4 we have that if $x, y \in G^{N}$ are such that $x_{i} \geq y_{i}$ for every $i \in S$, then for every game $V, l_{s}(x, V) \leq l_{S}(y, V)$.

The proposed conditions are a generalization of the condition imposed on an excess function for classical cooperative game without side payment proposed in Kalai (1975) to MCC game.

\section{Definition 4}

A payoff $x \in V$ is called individually rational if it belongs to the set

$I R(V)=\left\{x \in V^{N}:\right.$ for every $i \in N$ there is no $y \in V^{\{i\}}$ for which $\left.y_{i}>x_{i}\right\}$.

A payoff $x \in V$ are called group rational if it belongs to the set

$G R(V)=\left\{x \in V^{N}:\right.$ there is no $y \in V^{N}$ for which $y_{i}>x_{i}$ for every $\left.\mathrm{i} \in N\right\}$. 
Individual rationality means that no player agrees on a payoff "worse" than he can get acting individually. Group rationality says that each player tries to maximize his payoff.

\section{Theorem 1}

For any collection of excess functions $\left\{l_{S}\right\}_{S \in \mathcal{N}}$, for every game $V$

$\operatorname{core}(V)=\left\{x \in G R(V): l_{S}(x, V) \leq 0\right.$, for every $\left.S \in \mathcal{N} \backslash\{N\}\right\}$.

The proof can be found in Kruś, Bronisz (1993).

\section{Definition 5}

Let $\Theta(x)$ be the vector in $R^{|\mathcal{N}|-1}$ obtained by arranging values of the excess functions $l_{s}(x, V)$ of all coalitions $S$ in $\mathcal{N}, S \neq N$ in the nonincreasing order. The nucleolus is defined by

$N(V)=\left\{x \in I R(V): \Theta(x) \leq_{l e x} \theta(y)\right.$ for any $\left.y \in I R(V)\right\}$.

For any vectors $x, y \in R^{m}, x \leq_{l e x} y$ means that $x=y$, or that there is an integer $k$, $1 \leq k \leq m$, such that $x_{i}=y_{i}$, for $1 \leq i<k$ and that $x_{k}<y_{k}$.

\section{Theorem 2}

For any collection of excess functions $\left\{l_{S}\right\}_{S \in \mathcal{N}}$, for every game $V$, the nucleolus $N(V)$ is nonempty. Moreover, if the core is nonempty then

$N(V) \subset \operatorname{core}(V)$.

The proof can be found in Kruś, Bronisz (1993).

\section{PROPOSED EXCESS FUNCTION, NUCLEOLUS AND THEIR PROPERTIES}

Let $\underline{x}=\left(\underline{x}_{1}, \underline{x}_{2}, \ldots \underline{x}_{n}\right) \in G^{N}$ and $\bar{x}=\left(\bar{x}_{1}, \bar{x}_{2}, \ldots, \bar{x}_{n}\right) \in G^{N}$ be given points such that $\underline{x} \in w I R(V), \underline{x}_{i} \in V^{\{i\}}$ and $\bar{x}>>\underline{x}$. A point $\underline{x}$ can be treated as a preferred payoff of players acting individually, and $\bar{x}$ as a payoff describing the players "aspiration levels". According to aspiration function approach Wierzbicki $(1982,1986)$, the payoffs $\underline{x}$ and $\bar{x}$ define a desirable improvement direction of the players payoffs. The improvement direction (assuming a normalization among the players) can be formulated by:

$$
\begin{aligned}
& w(\underline{x}, \bar{x}) \in G^{N}, w(\underline{x}, \bar{x})=\left(w_{1}(\underline{x}, \bar{x}), \ldots, w_{n}(\underline{x}, \bar{x})\right), \\
& w_{i}(\underline{x}, \bar{x}) \in G_{i}=R^{k_{i}}, w_{i}(\underline{x}, \bar{x})=\left(w_{i 1}(\underline{x}, \bar{x}), \ldots, w_{i k_{i}}(\underline{x}, \bar{x})\right), \text { for } i \in N, \\
& w_{i j}(\underline{x}, \bar{x})=\frac{\bar{x}_{i j}-\underline{x}_{i j}}{\sum_{j=1}^{k_{i}}\left(\bar{x}_{i j}-\underline{x}_{i j}\right)} .
\end{aligned}
$$


It can be easy noticed that for every $i \in N$, $\sum_{j=1}^{k_{i}} w_{i j}(\underline{x}, \bar{x})=1$.

Let $w^{S}(\underline{x}, \bar{x})=\left(w_{i}(\underline{x}, \bar{x})\right)_{i \in S} \in G^{S}$. In our approach, we are looking for solution concepts to the game which depend on preferences of every player. The composition of the players preferences is expressed by the points $\underline{x}$ and $\bar{x}$. The normalization of weights assures anonymity of the players.

For given points $\underline{x}$ and $\bar{x}$, we propose the following function $l_{S}$ :

$l_{S}(x, V)=h_{S}(x, V, \underline{x}, \bar{x})=\sup \left\{t \in R: x^{S}+t \cdot \frac{t^{S}(\underline{x}, \bar{x})}{s} \circ w^{S}(\underline{x}, \bar{x}) \in V^{S}\right\}$,

where:

$s$ denotes the number of players in $S$,

$t(\underline{x}, \bar{x})=\left(t_{1}(\underline{x}, \bar{x}), \ldots t_{n}(\underline{x}, \bar{x})\right) \in R^{n}, t^{S}(\underline{x}, \bar{x})=\left(t_{i}(\underline{x}, \bar{x})\right)_{i \in S}$,

$t_{i}(\underline{x}, \bar{x})=\sup \left\{t \in R:\left(\underline{x}_{i}+t \cdot w_{i}(\underline{x}, \bar{x})\right) \in P^{\{i\}}\left(V^{N}\right)\right\}$,

$P^{S}: G^{N} \rightarrow G^{S}$ is the projection of $G^{N}$ on $G^{S}$, i.e. $P^{S}\left(V^{N}\right)=\left\{x^{S}: x \in V^{N}\right\}$,

$t(\underline{x}, \bar{x}) \circ w(\underline{x}, \bar{x})=\left(t_{1} \cdot w_{1}(\underline{x}, \bar{x}), \ldots, t_{n} \cdot w_{n}(\underline{x}, \bar{x})\right) \in G^{N}$,

$t^{S}(\underline{x}, \bar{x}) \circ w^{S}(\underline{x}, \bar{x})=\left(t_{i} \cdot w_{i}(\underline{x}, \bar{x})\right)_{i \in S} \in G^{S}$.

It has been shown Kruś, Bronisz (1993), that the following lemma fulfills:

\section{Lemma 1}

For given $\underline{x}$ and $\bar{x}$, the function $h_{S}(x, V, \underline{x}, \bar{x})$ is an excess function for MCC game.

\section{Definition 6} $i \in N$

A payoff $u(\underline{x}, \bar{x})=\left(u_{i}(\underline{x}, \bar{x})\right)_{i \in N}$ is an utopia payoff relative to $\underline{x}$ and $\bar{x}$ if for each $u_{i}(\underline{x}, \bar{x})=\sup \left\{x_{i} \in P^{\{i\}}\left(V^{N}\right): x_{i}=\underline{x}_{i}+t \cdot\left(\bar{x}_{i}-\underline{x}_{i}\right)\right.$ for some $\left.t \in R\right\}$.

It is easy to notice that the following equations are satisfied:

$u(\underline{x}, \bar{x})=\underline{x}+t(\underline{x}, \bar{x}) \circ w(\underline{x}, \bar{x})$,

$h_{S}(x, V, \underline{x}, \bar{x})=h_{S}(x, V, \underline{x}, u(\underline{x}, \bar{x}))$,

and for any $z \in G^{N}$ such that $z=\underline{x}+t \cdot w(\underline{x}, \bar{x})$ for some $t \in R, t>0$,

$h_{S}(x, V, \underline{x}, \bar{x})=h_{S}(x, V, \underline{x}, z)$.

From the equations it follows that the excess function $h_{S}(x, V, \underline{x}, z)$ depends only on $\underline{x}$ and on direction $w$ generated by $\bar{x}$, but does not depend on value of $\bar{x}$. The players $i$ in $N$ are balanced with weights, which are proportional to the distances of $u_{i}-\underline{x}_{i}$. The distance for particular player describes his "bargaining power" in the MCC game. 


\section{Definition 7}

Let $T=\left(T_{1}, \ldots, T_{n}\right): G^{S} \rightarrow G^{S}$ be an arbitrary affine transformation such that $T_{i j} x=\left(a_{i j} \cdot x_{i j}+b_{i j}\right)$, where $a_{i j}>0$, for $i \in N, j=1,2, \ldots k_{i}$. We say that a solution concept $F(V)$ is invariant under positive affine transformation of criteria if

$F(T V)=T F(V)$.

\section{Proposition 1}

For given $\underline{x}$ and $\bar{x}$, the nucleolus $N(V, \underline{x}, \bar{x})$ generated by the function $h_{S}(x, V, \underline{x}, \bar{x})$ is invariant under positive affine transformations of criteria, i.e.

$N(T V, T \underline{x}, T \bar{x})=T N(V, \underline{x}, \bar{x})$.

Proof. Let $T$ be as in the definition 7 and let $T^{S}=\left(T_{i}\right)_{i \in S}: G^{S} \rightarrow G^{S}$. To proof the proposition 1 we show that for any coalition $S$, any $x \in G^{N}$, and any $t>0$,

$T^{S} x^{S}+t \cdot \frac{t^{S}(T \underline{x}, T \bar{x})}{s} \circ w^{S}(T \underline{x}, T \bar{x})=T^{S}\left(x^{S}+t \cdot \frac{t^{S}(\underline{x}, \bar{x})}{s} \circ w^{S}(\underline{x}, \bar{x})\right)$.

For any $i \in N$ and $j$ such that $1 \leq j \leq k_{i}$, from the above equations we have

$w_{i j}(T \underline{x}, T \bar{x})=\frac{a_{i j}\left(\bar{x}_{i j}-\underline{x}_{i j}\right)}{\sum_{j=1}^{k_{i}} a_{i j}\left(\bar{x}_{i j}-\underline{x}_{i j}\right)}$

and

$\frac{t_{i}(\underline{x}, \bar{x})}{\sum_{j=1}^{k_{i}}\left(\bar{x}_{i j}-\underline{x}_{i j}\right)}=\frac{t_{i}(T \underline{x}, T \bar{x})}{\sum_{j=1}^{k_{i}} a_{i j}\left(\bar{x}_{i j}-\underline{x}_{i j}\right)}$.

We obtain

$T_{i j} x_{i j}+t \cdot \frac{t_{i}(T \underline{x}, T \bar{x})}{s} \cdot w_{i j}(T \underline{x}, T \bar{x})=$

$a_{i j} x_{i j}+b_{i j}+t \cdot \frac{t_{i}(\underline{x}, \bar{x}) \cdot \sum_{j=1}^{k_{i}} a_{i j}\left(\bar{x}_{i j}-\underline{x}_{i j}\right)}{\sum_{j=1}^{k_{i}}\left(\bar{x}_{i j}-\underline{x}_{i j}\right) \cdot s} \cdot \frac{a_{i j}\left(\bar{x}_{i j}-\underline{x}_{i j}\right)}{\sum_{j=1}^{k_{i}} a_{i j}\left(\bar{x}_{i j}-\underline{x}_{i j}\right)}=$

$a_{i j}\left(x_{i j}+t \cdot \frac{t_{i}(\underline{x}, \bar{x})}{s} \cdot \frac{\left(\bar{x}_{i j}-\underline{x}_{i j}\right)}{\sum_{j=1}^{k_{i}}\left(\bar{x}_{i j}-\underline{x}_{i j}\right)}\right)+b_{i j}=T_{i j}\left(x_{i j}+t \cdot \frac{t_{i}(\underline{x}, \bar{x})}{s} \cdot w_{i j}(\underline{x}, \bar{x})\right)$.

Therefore the excess function $h_{s}(x, V, \underline{x}, \bar{x})$ is independent on positive affine transformation of criteria, i.e. for any $S \in \mathcal{N}$ and an arbitrary affine transformation $T$ such as in the definition 7 ,

$h_{S}(T x, T V, T \underline{x}, T \bar{x})=h_{S}(x, V, \underline{x}, \bar{x})$. 
From the definition of the nucleolus we have immediately the result of the proposition.

It can be verified that the nucleolus generated by the functions $h_{S}$ is a generalization to MCC games of the nucleolus originally defined in Schmeidler (1969) for unicriteria, cooperative games with side payments.

Let us assume that the game $V$ is such that subcoalitions containing more then one player and less then $n$ players are trivial, i.e. if $|S| \neq 1,|S| \neq N$ then

$V^{S}=\times_{i \in S} V^{\{i\}}$.

Let $\left(V^{N}, \underline{x}\right)$ be an $n$-person multicriteria bargaining problem (MCB problem) defined as in Bronisz, Kruś (1988), Kruś, Bronisz (1993). If the solution concept $f^{R}\left(V^{N}, \underline{x}, u\right)$ proposed in Bronisz, Kruś (1988) for MCB problem $\left(V^{N}, \underline{x}\right)$ is Pareto optimal in $V^{N}$ then it can be shown that

$N(V, \underline{x}, \bar{x})=f^{R}\left(V^{N}, \underline{x}, u(\underline{x}, \bar{x})\right)$.

The solution $f^{R}\left(V^{N}, \underline{x}, u\right)$ is a generalization (see Bronisz, Krus 1988) of the Raiffa-KalaiSmorodinsky solution originally defined and analysed for classical bargaining problem (i.e. if $k_{i}=1$ for every $i \in N$ ) in Raiffa (1953), Kalai, Smorodinsky (1975), Thomson (1980).

In the unicriteria case (i.e. if $k_{i}=1$ for every $i \in N$ ), if the subcoalitions are trivial, the nucleolus proposed here coincides with the original Imai solution to bargaining problem Imai (1983). The Imai solution lexicographically improves the Raiffa-Kalai-Smorodinsky solution if the last one is not Pareto optimal.

\section{CONCLUSIONS}

In the paper, multicriteria cooperative games without side payment have been formulated. Concepts of core, excess function and nucleolus are formulated and analysed. In our approach we follow the way applied by Kalai (1975) in the classical case of unicriterial payoffs of players, trying to generalize it on the case of multicriteria games. Main result consists in the proposition of a new excess function which is independent on affine transformations of criteria. The nucleolus generated by the function is invariant on affine transformations of the players criteria. It is shown that the nucleolus coincides with the Schmeidler nucleolus in case of unicriteria games with side payments, with generalized Raiffa-Kalai- Smorodinsky solution proposed and discussed in Kruś, Bronisz (1993), Bronisz, Kruś (1988) in the case of multicriteria bargaining problem and with Raiffa-Kalai-Smorodinsky solution Raiffa (1953); Kalai, Smorodinsky (1975) in the case of classical unicriteria bargaining problem.

Further research will be devoted to construction of interactive procedures supporting players in analysis of the multicriteria game and in selection of an agreeable, consistent to the players preferences payoff. The proposed nucleolus seems to be candidate for such a payoff. Other forms of excess function and nucleolus concepts formulated with use of the functions will be analysed. 


\section{REFERENCES}

Aumann, R.J. (1961) The Core of Cooperative Games without Side Payments. Trans. Amer. Math. Soc., 98, 539-52.

Aumann, R.J. and Maschler, M. (1964) The Bargaining Set for Cooperative Games, in Advances in Game Theory (eds. M. Dreshler, L.S. Shapley and A.W. Tucker), Annals of Mathematics Studies, No. 52, Princeton University Press, Princeton, New Jersey.

Bergstresser, K., Yu, P.L. (1977) Domination Structures and Multicriteria Problems in N-person Games. Theory and Decision, 8, 5-48.

Bronisz, P., Kruś, L. (1988) Application of Generalized Raiffa Solution to Multicriteria Bargaining Support, in System Modeling and Optimization (eds. M. Iri, K. Yajima), Lecture Notes in Control and Information Sciences, Vol. 113, Springer-Verlag.

Gembicki, F., Haimes, Y.Y. (1975) Approach to Performance and Multiobjective Sensitive Optimization: the Goal Attainment Method. IEEE Automatic Control AC-20, No. 6.

Kalai, E. (1975) Excess Functions for Cooperative Games without Sidepayments. SIAM J. Appl. Math., 29, No. 1.

Kalai, E., Smorodinsky, M. (1975) Other Solutions to Nash's Bargaining Problem. Econometrica, 43, 513-8.

Kruś L., Bronisz, P., Lopuch, B. (1990) MCBARG Enhanced. A System Supporting Multicriteria Bargaining, Collaborative Paper, CP-90-06, IIASA, Laxenburg, Austria.

Kruś L., Bronisz, P. (1993) Some New Results in Interactive Approach to Multicriteria Bargaining, in User-Oriented Methodology and Techniques of Decision Analysis and Support (eds. J. Wessels, A.P. Wierzbicki), Lecture Notes in Economics and Mathematical Systems, Vol. 397, Springer-Verlag.

Kruś, L., Bronisz, P. (1993) On Multicriteria Cooperative Games without Side-payments. Research Report, Systems Research Institute, Polish Academy of Sciences, Warsaw, Poland.

Kruś L., Bronisz, P. (1994) On n-person Noncooperative Games Describe in Strategic Form. Annals of Operation Research. 51, J.C. Balzer AG, Sci. Publ., 83-97.

Peleg, B. (1963) Solutions to Cooperative Games without Side Payments. Trans, Amer. Math. Soc., 106, 280-92.

Raiffa, H. (1953) Arbitration Schemes for Generalized Two-Person Games. Annals of Mathematics Studies, 28, Princeton University Press, Princeton, New Jersey, 361-87.

Stearns, R. (1964) On the Axioms for a Cooperative Game without Side Payments. Proc. Amer. Math. Soc, 15, 82-86.

Thomson, W. (1980) Two Characterization of the Raiffa Solution. Economic Letters, 6, 225-31.

Wierzbicki, A.P. (1982) A Mathematical Basis for Satisficing Decision Making. Mathematical Modelling, 3, 391-405.

Wierzbicki, A.P. (1986) On the Completeness and Constructiveness of Parametric Characterization to Vector Optimization Problems. OR-Spectrum, 8, 73-87. 